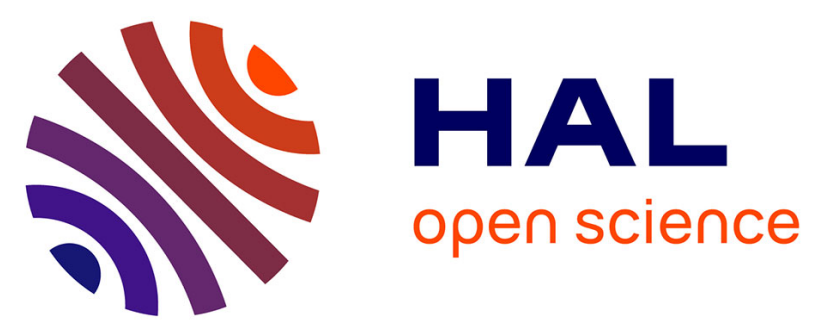

\title{
Annealing effect on the magnetization reversal and Curie temperature in a GaMnAs layer
}

\author{
H. Riahi, W. Ouerghui, L. Thevenard, Catherine Gourdon, M.A. Maaref, A. \\ Lemaître, O. Mauguin, Christophe Testelin
}

\section{- To cite this version:}

H. Riahi, W. Ouerghui, L. Thevenard, Catherine Gourdon, M.A. Maaref, et al.. Annealing effect on the magnetization reversal and Curie temperature in a GaMnAs layer. Journal of Magnetism and Magnetic Materials, 2013, 342, pp.149-151. 10.1016/j.jmmm.2013.04.034 . hal-01229172

\section{HAL Id: hal-01229172 \\ https://hal.science/hal-01229172}

Submitted on 14 Dec 2015

HAL is a multi-disciplinary open access archive for the deposit and dissemination of scientific research documents, whether they are published or not. The documents may come from teaching and research institutions in France or abroad, or from public or private research centers.
L'archive ouverte pluridisciplinaire HAL, est destinée au dépôt et à la diffusion de documents scientifiques de niveau recherche, publiés ou non, émanant des établissements d'enseignement et de recherche français ou étrangers, des laboratoires publics ou privés. 


\title{
Annealing effect on the magnetization reversal and Curie temperature in a GaMnAs layer
}

\author{
H. Riahi ${ }^{a}$, W. Ouerghui ${ }^{a^{*}}$ L. Thevenard ${ }^{b}$, C. Gourdon ${ }^{b}$, M. A. Maaref ${ }^{\text {a }}$, A. Lemaître ${ }^{\text {c, }}$ O. \\ Mauguin, C. Testelin ${ }^{\mathrm{b}}$ \\ ${ }^{a}$ Unité de Recherche de Physique des Semi-conducteurs et Capteurs, Institut Préparatoire aux \\ Etudes Scientifiques et Technologiques, Université de Carthage, BP 51, la Marsa 2070, \\ Tunisia. \\ ${ }^{\mathrm{b}}$ Institut des Nanosciences de Paris, Université Pierre et Marie Curie, CNRS-UMR 7588, 4 \\ Place Jussieu, 75005 Paris, France. \\ ${ }^{\mathrm{c}}$ Laboratoire de Photonique et Nanostructures, CNRS, Marcoussis, France.
}

\begin{abstract}
:
Vibrating Sample Magnetometer measurements were performed on a ferromagnetic $(\mathrm{Ga}, \mathrm{Mn}) \mathrm{As}$ thin film. We report Curie temperature $\left(\mathrm{T}_{\mathrm{c}}\right)$ up to $142 \mathrm{~K}$ in annealed $200 \mathrm{~nm}$ GaMnAs layer. This result is remarkable and comparable with the $T_{c}$ obtained in GaMnAs for small thicknesses $t<50 \mathrm{~nm}$. Our result reveals the high quality of the sample albeit the presence of 3 different chemical species, and a large thickness. After comparison with previous work obtained in GaMnAs, we show that for film of up to $t=200 \mathrm{~nm}$ the out diffusion based annealing process is not thickness limited.
\end{abstract}

Keywords: GaMnAs, Annealing, Carrier density and Curie temperature

*Corresponding author E-mail:ouerghuiwalid@yahoo.fr

\section{Introduction:}

The discovery of ferromagnetism in dilute magnetic semi-conductors (III,Mn)V has made it possible to demonstrate a number of new principles of spintronic device operations [1,2]. Their exact mechanisms of the magnetic interaction are still under discussion. Ferromagnetism in (Ga,Mn)As layers is commonly related to magnetic exchange interaction between the conduction holes and localized magnetic moments of the $\mathrm{Mn}_{\mathrm{Ga}}$ atoms ( $\mathrm{Mn}$ atoms located in Ga sites) [3]. The ferromagnetic ordering temperature $\left(\mathrm{T}_{\mathrm{c}}\right)$ of GaMnAs is directly related to the content of $\mathrm{Mn}$ and the holes density. Several groups shows that GaMnAs layers with high Mn doping are not suited in the framework of the Zener mean field [4.5]. They prove that only a fraction of the Mn dopant is magnetically active. Indeed, due the limited solubility of $\mathrm{Mn}$ in bulk GaAs, the low temperature conditions necessary for epitaxial growth of GaMnAs, induces defects such as Mn interstitials and As antisites that act as compensating donors and hence suppress ferromagnetic ordering [6,7]. The Curie temperature in GaMnAs strongly depends on the growth, in particular on the amount of compensating defects, i.e., the Mn atoms on interstitial 
positions $\mathrm{Mn}_{\mathrm{I}}$ (close either to $\mathrm{As}$ or $\mathrm{Ga}$ sublattices) and As antisites on the $\mathrm{Ga}$ sublattice [8]. Various techniques have been proposed to increase $T_{c}$ by careful annealing of $\mathrm{MBE}$-prepared samples - it is possible to increase the $T_{c}$ in GaMnAs [9]. Several factors act to favoring higher $T_{c}$. Indeed the growth parameters and postgrowth annealing play a crucial role in limiting $\mathrm{T}_{\mathrm{c}}$. Wang et al. have studied the effect of these two parameters and they found a linear dependence of $\mathrm{T}_{\mathrm{c}}$ and $\mathrm{M}_{\mathrm{s}}$ with Mn moment density [10]. The highest Curie temperature up to $190 \mathrm{~K}$ was obtained for annealing temperatures $\mathrm{T}_{\mathrm{a}}$ just below the growth temperature and with $10 \%$ effective Mn concentration [11], while long annealing times and low annealing temperatures result an increase of $\mathrm{T}_{\mathrm{c}}[12,13]$.

In this work, we have investigated the higher qualities of a $200 \mathrm{~nm}$ thick (Ga,Mn)As layer through a characterization by X-ray diffraction and VSM techniques. We reported the annealing effect on Curie temperature and we obtained a high $T_{c}$ in spite of the large thickness for GaMnAs contrary to previous works.

\section{Samples growth and experimental details:}

The samples under study have been grown by low temperature molecular beam epitaxy (LTMBE). It has a structure consisting of a $200 \mathrm{~nm}$ layer of $\mathrm{Ga}_{1-\mathrm{x}} \mathrm{Mn}_{\mathrm{x}}$ As deposited on a GaAs (100) substrate. In a first approximation and without taking into account the exact location of $\mathrm{Mn}$ atoms (interstitial or subtitutional sites), the $\mathrm{Mn}$ concentration was estimated by high resolution x-ray diffraction [14]. The $(\mathrm{Ga}, \mathrm{Mn})$ As layer was deposited at $713^{\circ} \mathrm{C}$.
After the growth, the sample was thermally annealed under $\mathrm{N}_{2}$ atmosphere at $200^{\circ} \mathrm{C}$ for $7 \mathrm{~h}$. We have studied a GaMnAs sample, as grown (a) and annealed (b). The nominal $\mathrm{Mn}$ concentration was around $\mathrm{x}=0.1$. We applied a magnetic field in the plane of the sample along [1-10], and varied it from -500 Oe to $500 \mathrm{Oe}$.

\section{Results and discussion:}

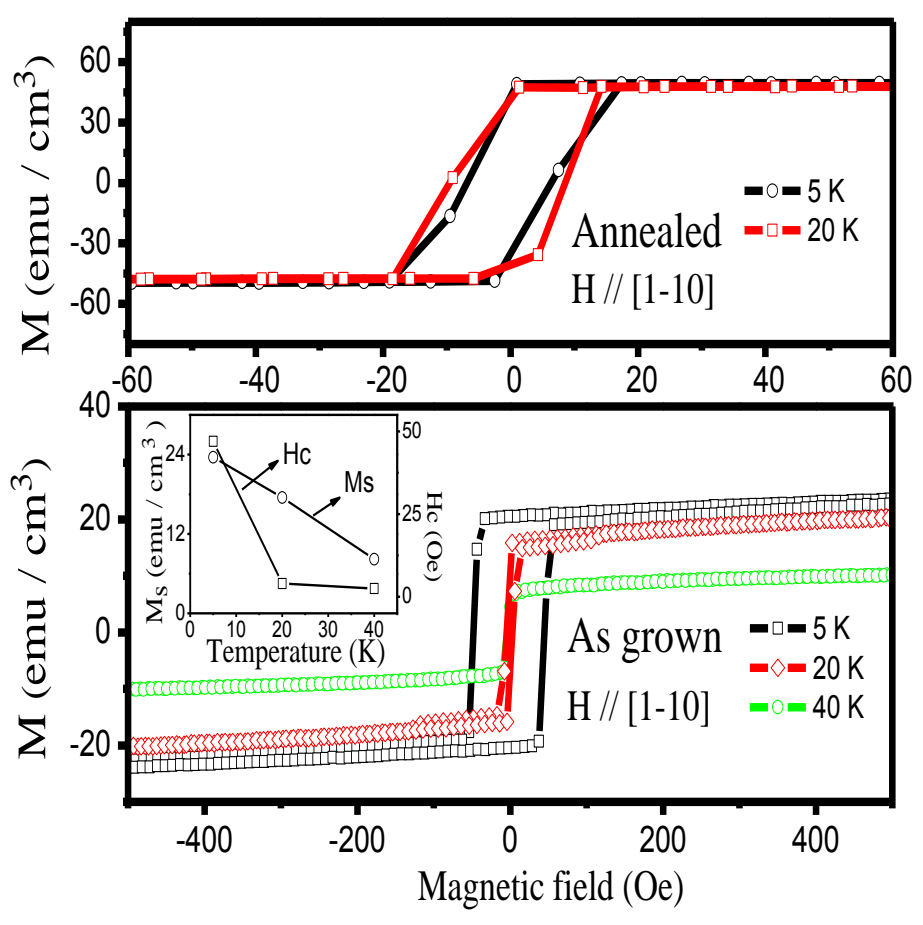

Fig.1. Magnetization curves as a function of the magnetic field along [1-10] for the as grown (a) and the annealed (b) GaMnAs layer. $\mathrm{T}=5 \mathrm{~K}$ (black line), $\mathrm{T}=20 \mathrm{~K}$ (red line), $\mathrm{T}=40 \mathrm{~K}$ (green line). The inset shows the dependence of both the saturation magnetization and the coercive field as a function of temperature for the As-grown GaMnAs layer.

Fig.1 presents the VSM data as a function of the magnetic field for the GaMnAs sample, both before and after annealing. The data shows a decrease of the saturation 
magnetization $\left(\mathrm{M}_{\mathrm{s}}\right)$ with increasing temperature. Indeed, for $\mathrm{T}=5 \mathrm{~K}$, the $\mathrm{M}_{\mathrm{s}}$ is in the vicinity of $23.6 \mathrm{emu} / \mathrm{cm}^{3}$ and the hysteresis loop is square. At higher temperature, it loses this character, and the magnetization reversal occurs at lower field, $\mathrm{M}_{\mathrm{s}} \approx 17.5 \mathrm{emu} / \mathrm{cm}^{3}$ at $\mathrm{T}=20 \mathrm{~K}$ and $\mathrm{M}_{\mathrm{s}} \approx 8 \mathrm{emu} / \mathrm{cm}^{3}$ at $\mathrm{T}=40 \mathrm{~K}$ (Inset .Fig.1). This modification of $\mathrm{M}_{\mathrm{s}}$ and the slope of hysteresis loops can be explained by a result from a competition in the plan of the layer between the cubic anisotropy $\left(\mathrm{K}_{4 \mathrm{par}}\right)$ according to [100] and growth uniaxial anisotropy $\left(\mathrm{K}_{4 \mathrm{perp}}\right)$ according to [110]. In addition, at low temperature the cubic anisotropy dominates the uniaxial contribution. However, at higher temperature the latter becomes stronger [15-17].

We also noticed that the value of the coercive field $\left(\mathrm{H}_{\mathrm{c}}\right)$ is fairly high at low temperature (Inset. Fig.1). It decreases abruptly to $45 \mathrm{Oe}$ at $\mathrm{T}=5 \mathrm{~K}$ from $4 \mathrm{Oe}$ and 2.5 respectively at $\mathrm{T}=20 \mathrm{~K}$ and $40 \mathrm{~K}$. After annealing, we observe that the saturation magnetization increases abruptly to $48 \mathrm{emu} / \mathrm{cm}^{3}$ for both $\mathrm{T}=5 \mathrm{~K}$ and $20 \mathrm{~K}$. The difference between the shapes of the two hysteresis loops disappears. This is due to removal of antiferromagnetically coupled $\mathrm{Mn}_{\mathrm{Ga}}-\mathrm{Mn}_{\mathrm{I}}$ pairs, which does take part in the ferromagnetic phase in the asgrown sample [18].

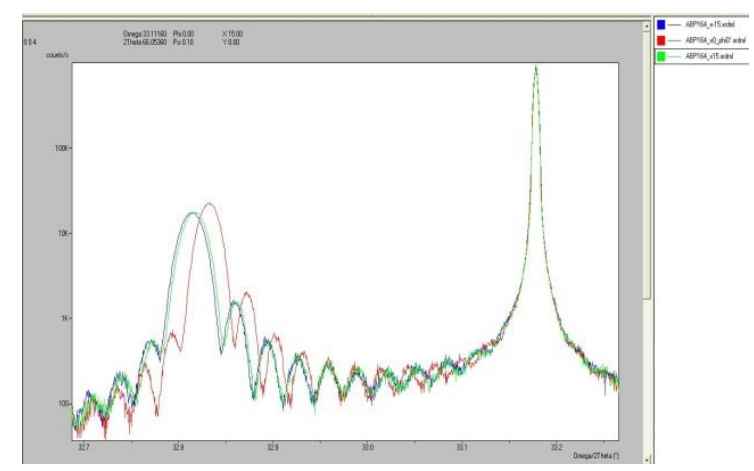

Fig. 2. X-ray diffraction scans for GaMnAs layer, in the center (red line) and to about $15 \mathrm{~mm}$ in the left and in the right of the center (blue and green lines).

The high resolution X-ray rocking curves around (004) reflection are shown in Fig. 2 for the annealed GaMnAs sample. The sharp peak $33.18^{\circ}$ corresponds to the diffraction by the GaAs substrate. The GaMnAs diffraction is located in the lower angle side, compared to the GaAs peak, $\mathrm{a}_{\text {per }}$ is therefore larger than $\mathrm{a}_{\text {sub }}$; the GaMnAs sample is under compressive strain on GaAs, in this sample, $\Delta a / a_{\text {sub }}=9400 \mathrm{ppm}$ is high indicating that the rather large amount of Mn atoms have been inserted in the matrix (close to 11.3 $\%$ ). We further noticed that the lattice mismatch is more significant close to the edges of plate than in the center. We found $9900 \mathrm{ppm}$ and $9820 \mathrm{ppm}$ respectively to about $15 \mathrm{~mm}$ in the left and in the right of the center.

This result would therefore suggest that annealing favors a rather large reduction of the interstitial concentration in the following sample.

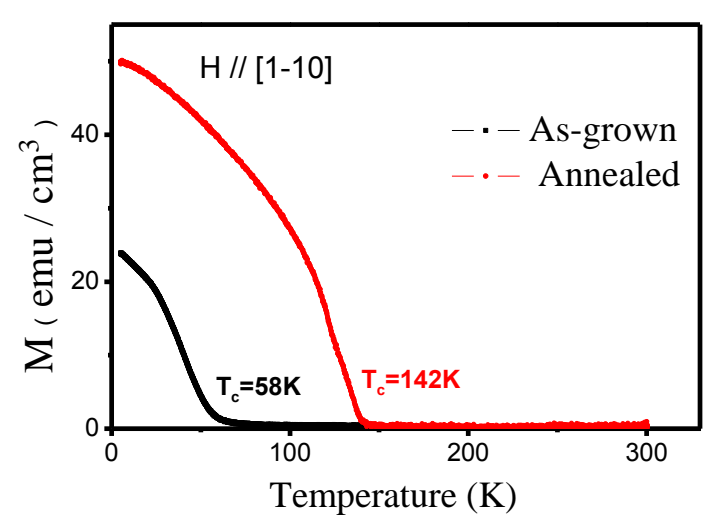

Fig.3. Magnetization curves for both as grown and annealed GaMnAs layer as a function of temperature. A static magnetic field of 500 Oe is applied for the as-grown layer and 100 Oe for the annealed one 
The temperature dependence of the magnetization $\mathrm{M}(\mathrm{T})$ is shown in Fig.3. We applied a magnetic field in plane for the two layers $(\mathrm{H}=500 \mathrm{Oe}$ for as-grown, and 100 Oe for annealed). The Curie temperature of As-grown $200 \mathrm{~nm}$ thick layers is typical for ferromagnetic GaMnAs samples [19], with a $T_{c}$ about 58 $\mathrm{K}$. Through the annealing technique, we note that $\mathrm{T}_{\mathrm{c}}$ increases up to $142 \mathrm{~K}$ (Fig. 3). Indeed, this increase may therefore be related to the removal of $\mathrm{Mn}$ ions in GaMnAs that occupy interstitial sites $\left(\mathrm{Mn}_{\mathrm{I}}\right)$. Since $\mathrm{Mn}_{\mathrm{I}}$ acts as a donor and hence compensates the holes, optimal annealing increases the hole density and correspondingly enhances $T_{c}$. So we can improve the magnetic properties of this sample by reducing the amount of compensating defects [20].

In addition to the effect of annealing, an important clue to limitations on $T_{c}$ in GaMnAs comes from the thickness of samples [20].

The effect of film thickness on the distribution of Mn atoms at various lattices sites in $(\mathrm{Ga}, \mathrm{Mn})$ As thin films have been investigated [21]. The authors quoted find that for film thickness less than $60 \mathrm{~nm}$ the growth surface acts as a sink facilitating the out diffusion of $\mathrm{Mn}$ interstitials $\mathrm{Mn}_{\mathrm{I}}$, and thus reducing its concentration in the film. The out diffused $\mathrm{Mn}_{\mathrm{I}}$ accumulate on the surface layer and do not participate in the ferromagnetism of the film. For thin films less than $15 \mathrm{~nm}$ thick, no $\mathrm{Mn}_{I}$ can be detected. Because of the absence of compensating $\mathrm{Mn}_{\mathrm{I}}$ defects, higher $\mathrm{T}_{\mathrm{c}}$ can be achieved for such extremely thin $\mathrm{Ga}_{1-\mathrm{x}} \mathrm{Mn}_{\mathrm{x}}$ As layers.

In a previous work, $T_{c}$ 's exceeding the 110 $\mathrm{K}$ limit have been reported in thin $\mathrm{Ga}_{1-x} \mathrm{Mn}_{x}$ As films ( $<50 \mathrm{~nm}$ thick) after low temperature annealing [20,22]. $\mathrm{Ku}$ et al. [20] noted that, while they achieved a maximum $T_{c}$ of $150 \mathrm{~K}$ for $20 \mathrm{~nm}$ $\mathrm{Ga}_{1-x} \mathrm{Mn}_{x}$ As films, they did not succeed in achieving $T_{c}>110 \mathrm{~K}$ (after annealing) for samples thicker than $50 \mathrm{~nm}$. In very recent study on $150 \mathrm{~nm}$ GaMnAs sample with 10 $\%$ Mn doped, T. de Boer et al.[23] obtain a $\mathrm{T}_{\mathrm{c}}$ about $135 \mathrm{~K}$. In general, the lower Tc in thick sample was attributed for two reasons. Firstly, to the presence of $\mathrm{Mn}_{\mathrm{I}}$ which electrically compensate the $\mathrm{Mn}_{\mathrm{Ga}}$ acceptors and cancel the $\mathrm{Mn}_{\mathrm{Ga}}$ Spins [24.25]. Secondly, the out diffusion of $\mathrm{Mn}_{\mathrm{I}}$ to the surface was limited in thicker samples [21]. Here, we found a value after annealing of the Curie temperature up to $142 \mathrm{~K}$, which is remarkable in GaMnAs in spite of a $200 \mathrm{~nm}$ thickness. This result shows the good quality of the sample used in this work and excludes that the out diffused of $\mathrm{Mn}_{I}$ accumulate on the surface layer is limited in the thick sample under investigation.

It is clear in previous work that the effect of the thickness is less pronounced in GaMnAs layer with Mn-doped above 10 $\%$. Indeed Ben Hamida et al. [26] highlighted a reduction of this effect by the comparison between $25 \mathrm{~nm}$ and $100 \mathrm{~nm}$ GaMnAs films. We can notice that the high value of $\mathrm{T}_{\mathrm{c}}$ in this layer is remarkable since it is comparable to those authors reference samples with small t. Chiba et al. [27] obtain $T_{c}$ about $140 \mathrm{~K}$ for $4 \mathrm{~nm}$ GaMnAs layer with an annealing temperature $\mathrm{T}_{\mathrm{a}}=180^{\circ} \mathrm{C}$. Also Cubukcu et al. [28] reported a $\mathrm{T}_{c}$ about $130 \mathrm{~K}$ for an annealed $50 \mathrm{~nm}$ GaMnAs film with 10 percent of Mn. With $200 \mathrm{~nm}$ GaMnAs thick layer, we found a similar result to samples with small $t$ and thus prove that the Mn out diffusion is yet not significantly thicknesslimited. 


\section{Conclusion:}

To summarize, the magnetic proprieties of thick $\mathrm{Ga}_{0.9} \mathrm{Mn}_{0.1}$ As film are reported using the VSM technique. We have found that the post-growth annealing results in a dramatic enhancement of both Ms and Tc comparable with GaMnAs layers with small thicknesses. This result highlights the good quality of the sample and shows that the out diffusion mechanism is not limited to a thickness up to $200 \mathrm{~nm}$ under investigation contrary to the previous conclusion [21].

\section{References}

[1] T. Dietl, H. Ohno, and F. Matsukura, IEEE

Trans. Electron Devices. 54 (2007) 945.

[2] F. Matsukura, D. Chiba, and H. Ohno, in Semiconductors and Semimetals, edited by T. Dietl, D. D. Awschalom, M. Kaminska, and H. Ohno

(Academic, New York). 82 (2008), pp. 207- 240.

[3] J. Chang-Jian, Z. Cheng-Qiang, Z. Gang,

W. Wen-Jing, S. Gang, Y. Hui-Min, and H. QiFeng, Chin. Phys. Lett. 28 (9) (2011) 097101.

[4] Kh. Khazen, H. J. von Bardeleben, J. L. Cantin, A. Mauger, L. Chen and J. H. Zhao, Phys. Rev. B. 81 (2010) 235201.

[5] M. Dobrowolska, K. Tivakornsasithorn, X. Liu, J.

K. Furdyna, M. Berciu, K. M. Yu, and W. Walukiewicz, Nature Materials 11 (2012) 444.

[6] D. Chiba, K. M. Yu, W. Walukiewicz, Y. Nishitani, F. Matsukura, and H. Ohno, J. Appl. Phys. 103 (2008) 07D136.

[7] S. Mack, R. C. Myers, J. T. Heron, A. C. Gossard, and D. D. Awschalom. Appl. Phys. Lett. 92 (2008) 192502.

[8] Y. Nishitani. D. Chiba, F. Matsukura and H. Ohno, J. App. Phys. 103 (2008) 07D139.
[9] R. Mathieu, B. S. Sørensen, J. Sadowski, U. S“odervall,J.Kanski, P. Svedlindh, P. E. Lindelof, D. Hrabovsky, and E. Vanelle, Phys. Rev.B. 64 (2003) 184421.

[10] M. Wang, R. P. Campion, A. W. Rushforth, K. W. Edmonds, C. T. Foxon, and B. L. Gallagher, Appl. Phys. Lett. 93 (2008) 13210.

[11] L. Chen, S. Yan, P. F. Xu, J. Lu, W. Z. Wang, J. J. Deng, X. Qian, Y. Ji, and J. H. Zhao, App. Phys. Lett. 95 (2009) 182505.

[12] S. J. Potashnik, K. C. Ku, R. Mahendiran, S. H. Chun, R.F. Wang, N. Samarth, and P. Schiffer, Phys. Rev. B. 66 (2002) 012408.

[13] Kuryliszyn, T. Wojtowicz, X. Liu, J. K. Furdyna, W. Dobrowolski, J.-M. Broto, M. Goiran, O. Portugall, H. Rakoto, and B. Raquet, Acta Phys. Pol. A. 102 (2002) 659.

[14] Y. Nishitani, D. Chiba, M. Endo, M. Sawicki, F. Matsukura, T. Dietl, and H. Ohno, Phys. Rev. B. 81 (2010) 045208.

[15] X. Liu, Y. Sasaki, and J. K. Furdyna, Phys. Rev. B. 67 (2003) 205204.

[16] M. Sawicki, F. Matsukura, A. Idziaszek, T.Dietl, G. M. Schott,C. Ruester, C. Gould, G. Karczewski, G. Schmidt, and L. W. M,olenkamp, Phys. Rev. B. 70 (2004) 245325.

[17] V. Stanciu and P. Svedlinh, Appl. Phys. Lett. 87 (2005) 242509.

[18] J. Sadowski, J. Z. Domagała, J. Kanski, C.H. Rodriguez, F. Terki, S. Charar and D. Maude, Materials Science-Poland. 24 (2006) 3.

[19] O. Proselkov, D. Sztenkiel,W. Stefanowicz, M. Aleszkiewicz, J. Sadowski, T. Dietl, and M. Sawicki, Appl. Phys. Lett. 100 (2012) 262405.

[20] K. C. Ku, S. J. Potashnik, R. F. Wang, M. J. Seong, E. Johnston-Halperin, R. C. Meyers, S. H. Chun, A. Mascarenhas, A. C. Gossard, D. D. 
Awschalom, P. Schiffer, and N.Samarth, Appl. Phys. Lett. 82 (2003) 2302.

[21] K. M. Yu, W. Walukiewicz, T. Wojtowicz, J. Denlinger, M. A. Scarpulla, X. Liu, and J. K. Furdyna, App. Phys. Lett. 86 (2005) 042102.

[22] D. Chiba, K. Takamura, F. Matsukura, and H. Ohno, Appl. Phys. Lett. 82 (2003) 3020.

[23] T. de Boer, A. Gamouras, S. March, V. Novak, and K. C. Hall, Phys. Rev. B. 85(2012) 033202.

[24] K. M. Yu, W. Walukiewicz, T. Wojtowicz, I. Kuryliszyn, X. Liu, Y. Sasaki, and J. K. Furdyna, Phys. Rev. B. 65 (2002) 201303 (R).

[25] K. M. Yu, W. Walukiewicz, T. Wojtowicz, W. L. Lim, X. Liu, Y. Sasaki, M. Dobrowolska, and J. K. Furdyna, Phys. Rev. B. 68(2003) 041308 (R).

[26] A. Ben Hamida, N. Liebing, S. SerranoGuisan, S. Sievers, K. Pierz, and H. W. Schumacher. J. Magn. Soc. Jpn. 36 (2012) 49-53.

[27] D. Chiba, Y. Nishitani, F. Matsukura, and H. Ohno, Appl. Phys. Lett. 90 (2007) 122503.

[28] M. Cubukcu, H.J. von Bardeleben, J.L. Cantin, I. Vickridg, and A. Lemaitre, Thin. Solid. Films. 519 (2011) 8212-8214. 